\title{
THE UNUSUAL WEB OF SPILASMA TUBULOFACIENS, WITH TAXONOMIC NOTES ON THE SPECIES (ARANEAE: ARANEIDAE)*
}

\author{
By Diomedes Quintero, Jr. \\ Museum of Comparative Zoology, \\ Harvard University, Cambridge MA 02138
}

During December 1972 I had the opportunity to visit French Guiana to study some of its little known amblypygid fauna. While searching for amblypygids I came across the unusual web of an araneid, Spilasma tubulofaciens, and was able to make some abservations in the field.

I would like to acknowledge the gracious help and encouragement given by Dr. Herbert W. Levi, who also provided the laboratory facilities to complete this work. I would like also to thank Dr. J. J. de Granville for his hospitality and guidance in Cayenne, for the use of ORSTOM facilities in Saül, and for many other favors.

\section{Web of Spilasma tubulofaciens}

Figures 6-7

Spilasma tubulofaciens females were found in a forest patch clearing occupied with mixed growth of shrubs (mainly Rubiaceae and Leguminoseae), 2-3 $\mathrm{m}$ from the muddy banks of Crique Limonade, French Guiana. The suspension lines of the web were attached between leaves of a rubiaceous shrub, about I.2-1.4 $\mathrm{m}$ from the ground. In the middle they inserted at the apex of the conical retreat. The snare region was below, hanging obliquely, and had I6 radii and more than 28 turns, with no distinct frame threads. It showed numerous torn spaces and repairs, giving a general appearance of long use and disorganization. No major changes were introduced by the spiders during the night before they were collected next morning. The suspension lines were quite taut, forming nearly a straight horizontal line (Fig. 6). The outer surface of the conical retreat was rough, made up of diverse materials, predominantly remains of insect prey (small coleoptera, flies, etc.) and vegetable matter (protonema of mosses, small bark fragments, vegetable debris). This debris was firmly fixed to the surface by underlying, fine threads of silk. The inside of the retreat was smooth, lined with silk. The

*Manuscript received by the editor June 2, 1974. 

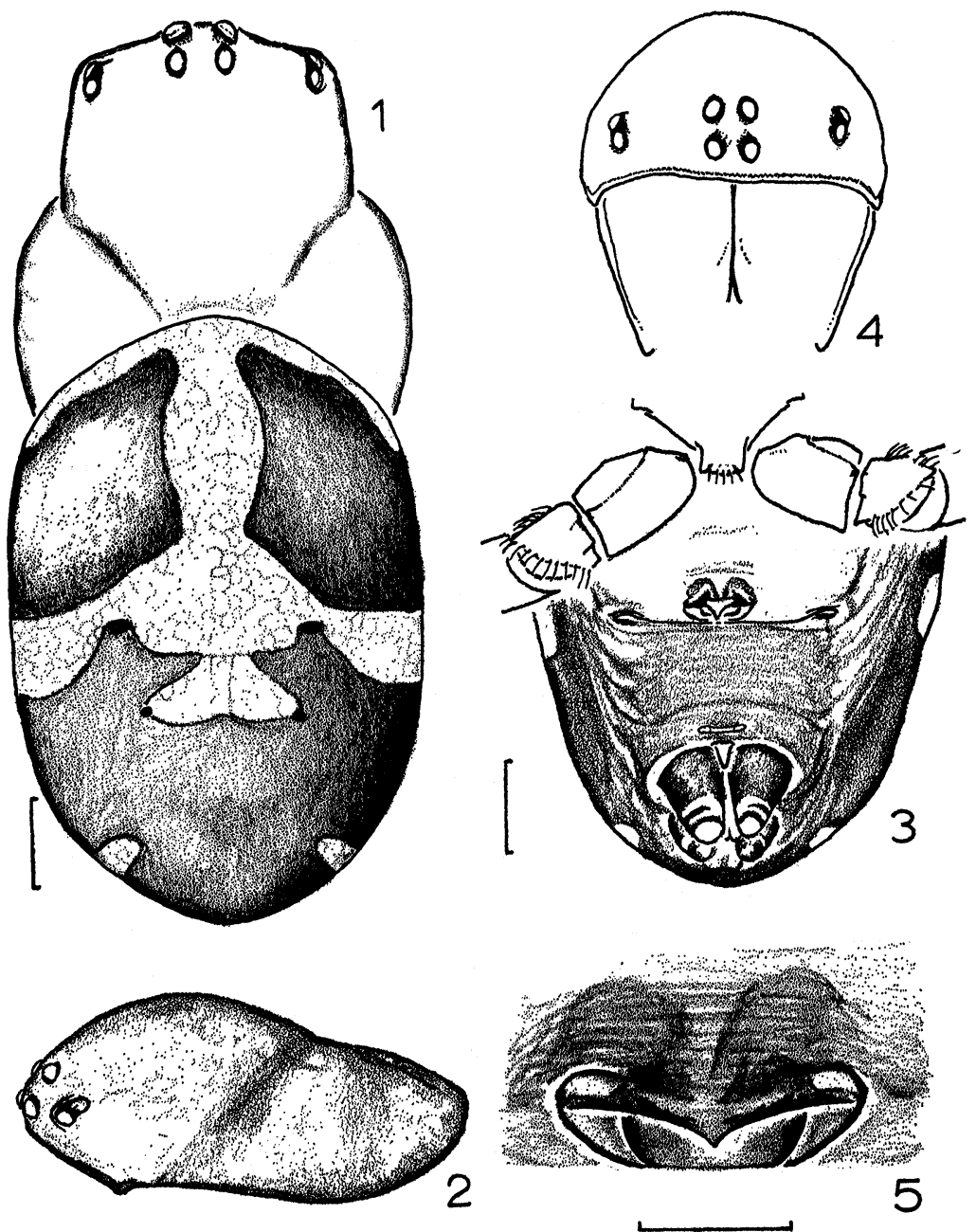

Figs. 1-5. Spilasma tubulofaciens (Hingston), female. 1. Dorsal view, appendages not represented. 2. Lateral view of carapace. 3. Ventral view of abdomen. 4. Head and part of chelicerae from in front. 5. Epigynum. Size indicators: Figs. 1-4, $0.5 \mathrm{~mm}$. Fig. $5,0.2 \mathrm{~mm}$. 


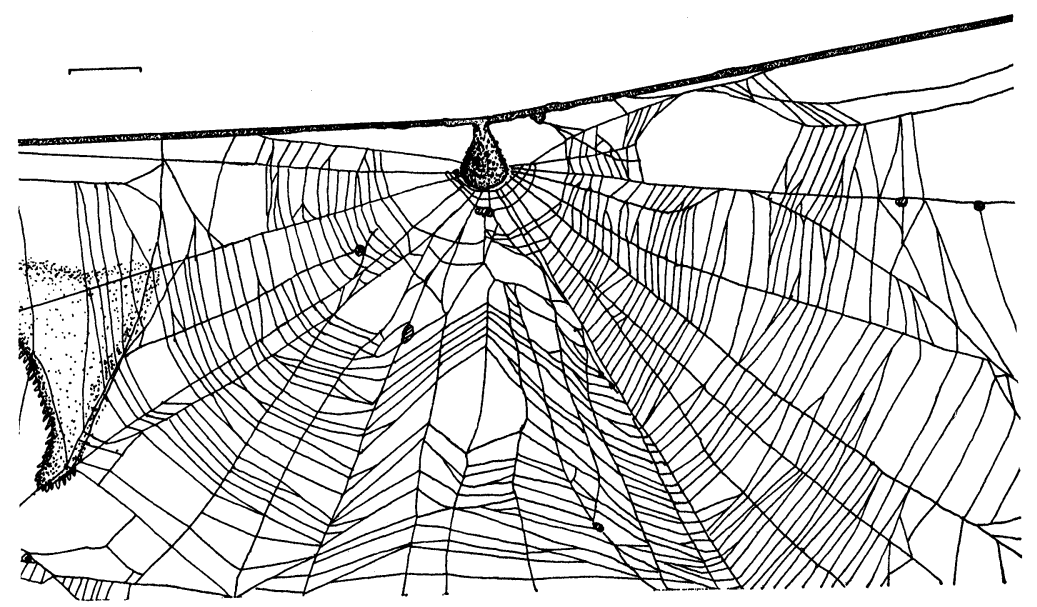

Fig. 6. S. tubulofaciens (Hingston), frontal view of web and retreat (entrance of retreat closed), drawn from photographs. Suspension lines shaded.

Size indicator: $10 \mathrm{~mm}$.

broad, lower end of the retreat had a transverse, single opening with two lips, the posterior lip being the longer. The lining of the anterior lip appeared thinner and more flexible. The supporting lines were strong, reinforced with silk, and contained numerous moss fragments, particularly close to the insertion on the retreat. There were also remains of insects and vegetable matter. The spider remains inside the retreat, and waits head down for its prey, a characteristic position of the orb-weaving spiders. When I offered living ants, which I placed on the lower corner of the catching web, the female dashed out of the retreat rapidly, wrapped its prey (Fig. 9), bit it, and promptly returned to the retreat, without eating the prey.

Discussion. By changing the position of the hub (coincident in this case with the retreat) to a peripheral, uppermost position, an additional load of tension has been placed on the suspension lines. Additional tension has also been brought to these lines by the taut, almost straight line, to which they have been drawn. Consequently the spider has carefully reinforced the lines with extra layers of silk, enclosing different building materials, and they no longer function in prey capture but to support the rest of the web and the retreat. It differs from $S$. artifex Simon, which Simon, in 1896 , described as hanging the retreat and catching web from a single perpendicular 

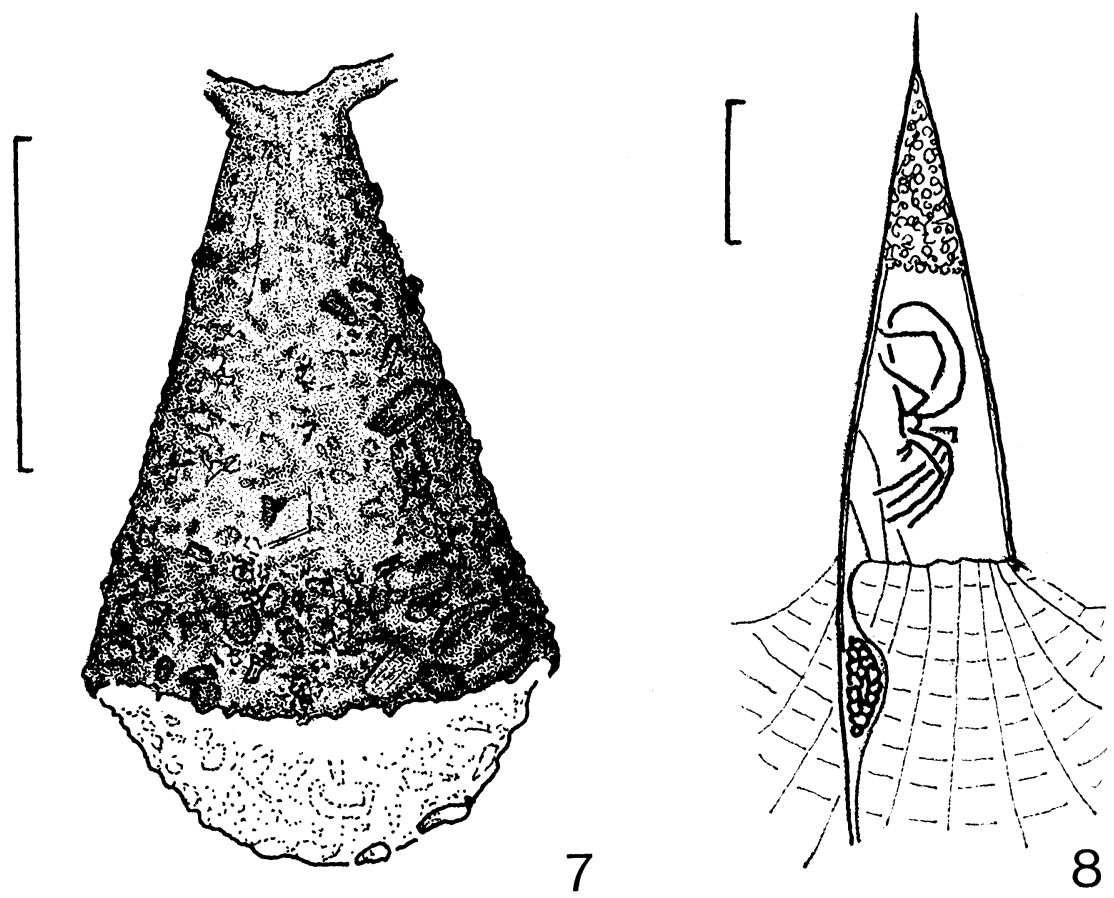

Fig. 7. S. tubulofaciens (Hingston), closer frontal view of the retreat, open. Posterior lip not shaded.

Fig. 8. S. artifex Simon, schematic representation of a cross section of the retreat. Posterior lip of the retreat hangs loose, enclosing mass of eggs (Modified from Simon, 1896, pl. 12, fig。4).

Size indicators: Figs. 7-8, $5 \mathrm{~mm}$. 
suspension line (Fig. 8) and having a catching web parallel to the floor, with an empty segment.

The numerous repairs in the web of $S$. tubulofaciens, the thickness of the suspension lines, and the elaborate construction oc the retreat all suggest that this web is long lasting (relative to the life span of the spider), and with time is repaired and modified. The retreat of the younger female had more space for occupancy than the retreat of the older female (as determined by body length as a percent of the length of the retreat), the space perhaps serves to accommodate additional growth of the spider without having to enlarge the retreat. Additional collections might verify this observation.

Nielsen ( 1928, pp. 534-535) has excellent photographs of Achaearanea saxatile (Koch), a theridiid, building a similar type of conical retreat on the ground and later scaffolding it to the desired height. It is likely that a similar (energy saving?) strategy is used by $S$. tubulofaciens, instead of making numerous trips to carry and assemble the materials above the ground, although above the ground modifications and repairs might be introduced at a later date.

The adaptive convergence of webs has been discussed recently by several authors (see Kullmann, 1972). Strangely, emphasis in their discussions has been placed on considering orb webs as indivisible entities which appear to have evolved as a unit. Although interactions must likely occur among the major structural components of the web (hub, retreat, and capture threads - snare), my impression is that each has distinct adaptations to cope with in response to environmental and physiological cues (e.g. the retreat to best hide the spider). The selective forces which might bring about evolutionary changes in these components, by selecting particular motor patterns of the spider, must differ and thus these components have evolved as distinct characters, although not totally independent.

Taxonomic notes

Spilasma tubulofaciens (Hingston), comb. nov.

Figures I-5

Epeira tubulofaciens Hingston, 1932, A naturalist in the Guiana Forest, E. Arnold \& Co., p. 366. From Guyana, Essequibo River. Web illustrations, pp. 150-153; no type material left.

Araneus tubulifaciens, Bonnet (1955, Bibliographia Araneorum, 2: 620, 80), makes emendation of specific name which is of Latin derivation.

Records. 2 우 (one immature) from French Guiana, Crique Limonade, 3-4 km S. of Saül, 21-22.VIII.1972. Adult + and retreats deposited in the MCZ, Harvard collection. 
In his 1932 work, Hingston described 27 new species from eight different genera collected during an expedition to Guyana in 1929. Hingston left no type material for his new species and his descriptions were very general, lacking diagnostic characters (Levi, I963, p. 493). Nevertheless, Hingston included descriptions and detailed sketches of the webs of his new species, which may help to validate some of his names, in some instances. Lehtinen (1967, p. 20I) considered that the only way to treat the species described by this author would be to propose all of them as "nomina dubia." I am convinced that the specimens which I have collected belong to one species described by Hingston as E. tubulofaciens. I base my assertion mainly on the unique abdominal and leg coloration patterns, and the remarkable architecture of the retreat and the catching web, which matches Hingston's descriptions. Although there is the possibility of sibling species, I have decided for the sake of stability in nomenclature to retain Hingston's name.

Description. Carapace, chelicerae (except claws), pedipalps, and dorsal surface of legs brownish yellow, with the two posterior legs a darker brown. Inner margin of endites white. Sternum and labium reddish brown. Carapace covered with fine-pointed bristles which become longer toward the anterior margin. Carapace with a welldefined cephalic suture. Ventral coloration of the two first legs is reddish orange but this pigmentation washed away after preserving the specimens in alcohol. Abdomen is longer than wide and slightly wider in its anterior half. Dorsum of abdomen with a broad, white $\mathrm{H}$-shaped mark over black background, positioned transversely on the anterior half. Near its middle, the posterior bar of the $\mathrm{H}$ mark has an additional smaller triangular white mark pointing anteriorly and two dorsal black sclerites. On its posterior third, latero-ventrally, two elongated white marks occur, one on each side of the abdomen. Venter with a light colored epigastrium and colulus. Anterior median eyes are largest and closely positioned, 0.7 diameter apart. Posterior medians one diameter apart. Laterals closely set on a common raised black-pigmented carapace projection. Total length $4.9 \mathrm{~mm}$. Carapace $2.6 \mathrm{~mm}$ long, $2.3 \mathrm{~mm}$ wide. First femur, $2.1 \mathrm{~mm}$; patella and tibia, $2.0 \mathrm{~mm}$; metatarsus, I.I mm; tarsus, $0.9 \mathrm{~mm}$. Second patella and tibia, I. $9 \mathrm{~mm}$; third, I. $3 \mathrm{~mm}$; fourth, I.7 $\mathrm{mm}$.

Diagnosis. Spilasma males are not known. Females of $S$. tubulofaciens have distinct body coloration and web construction, different from the only other South American species: $S$. tridecimguttata Simon 1896 from the Amazonas and $S$. artifex Simon 1896 from San Esteban, Venezuela. A third species, S. africana Simon 1903, 


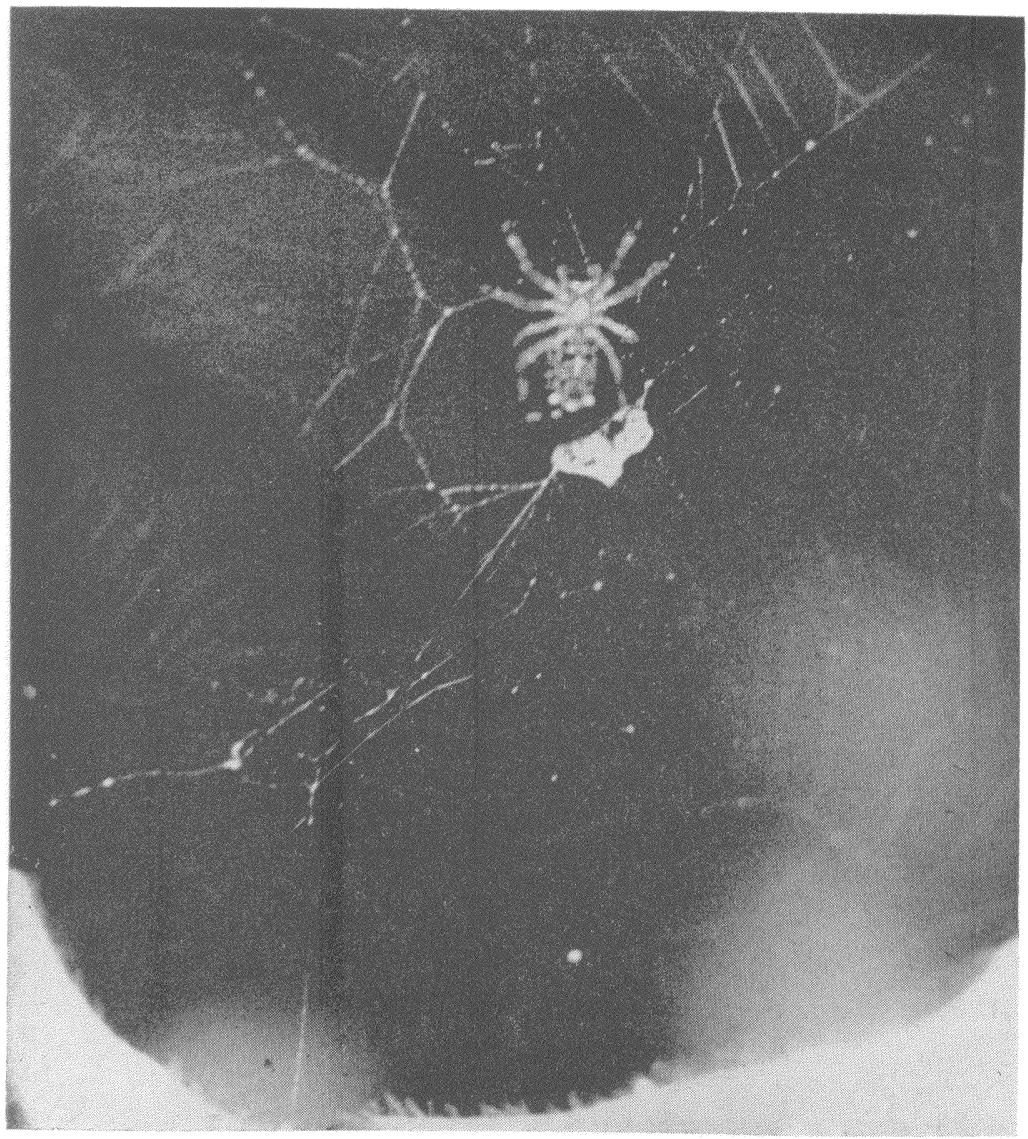

Fig. 9. Female of $S$. tubulofaciens wrapping prey on web. 
is only known from Equatorial Guinea. Hingston (1932, p. 366) described a species, E. sacculifaciens, with similar conical retreat and web architecture to $S$. tubulofaciens, which, I suspect, will eventually be ascribed to the genus Spilasma when new material is collected. Its reported size, $1.5 \mathrm{~mm}$, suggests it might be an immature specimen as the other known species of Spilasma range from 3 to $6 \mathrm{~mm}$ in length.

\section{BONNET, P.}

\section{References Cited}

1955. Bibliographia Araneorum, 2: 620, 80. Toulouse.

Hingston, R. W. C.

1932. A naturalist in the Guiana forest. E. Arnold \& Co., London. Kullmann, E. J.

1972. The convergent development of orb-webs in cribellate and ecribellate spiders. Am. Zoologist, 12: 395.

Levi, H. W.

1963. American spiders of the genus Theridion (Araneae: Theridiidae). Bull. Mus. Comp. Zool., $129(10): 493$.

Lehtinen, P. T.

1967. Classification of the cribellate spiders and some allied families. Ann. Zool. Fennici, 4: 201.

Nielsen, E.

1928. De Danske Edderkoppers Biologi. Denmark (pp. 521-535). Simon, E.

1892-1895. Histoire Naturelle des Araignees. I. Paris.

1896. Etudes Arachnologiques. Ann. Soc. Entomol. France, 65: 465-510, $1 \mathrm{pl}$. 

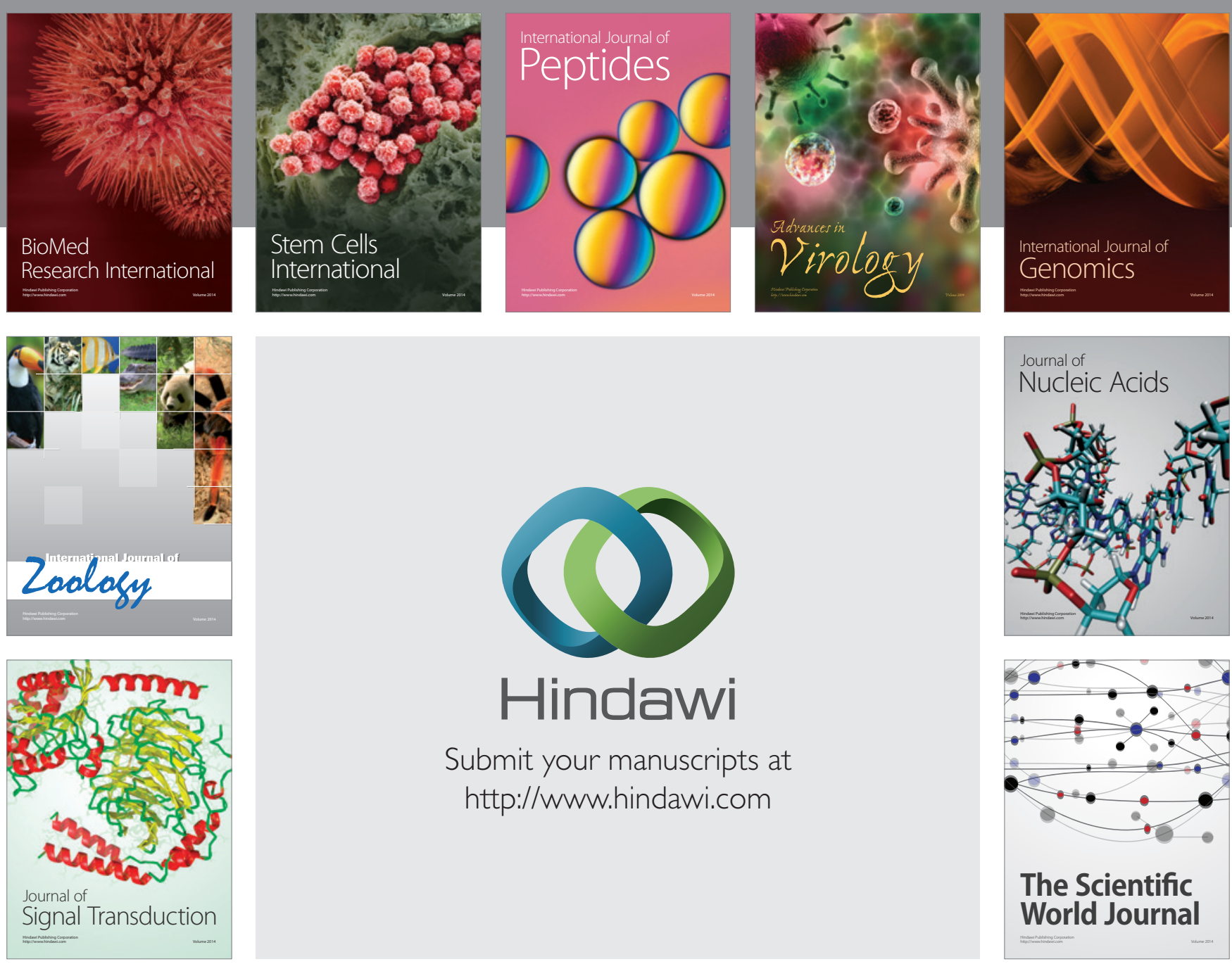

Submit your manuscripts at

http://www.hindawi.com
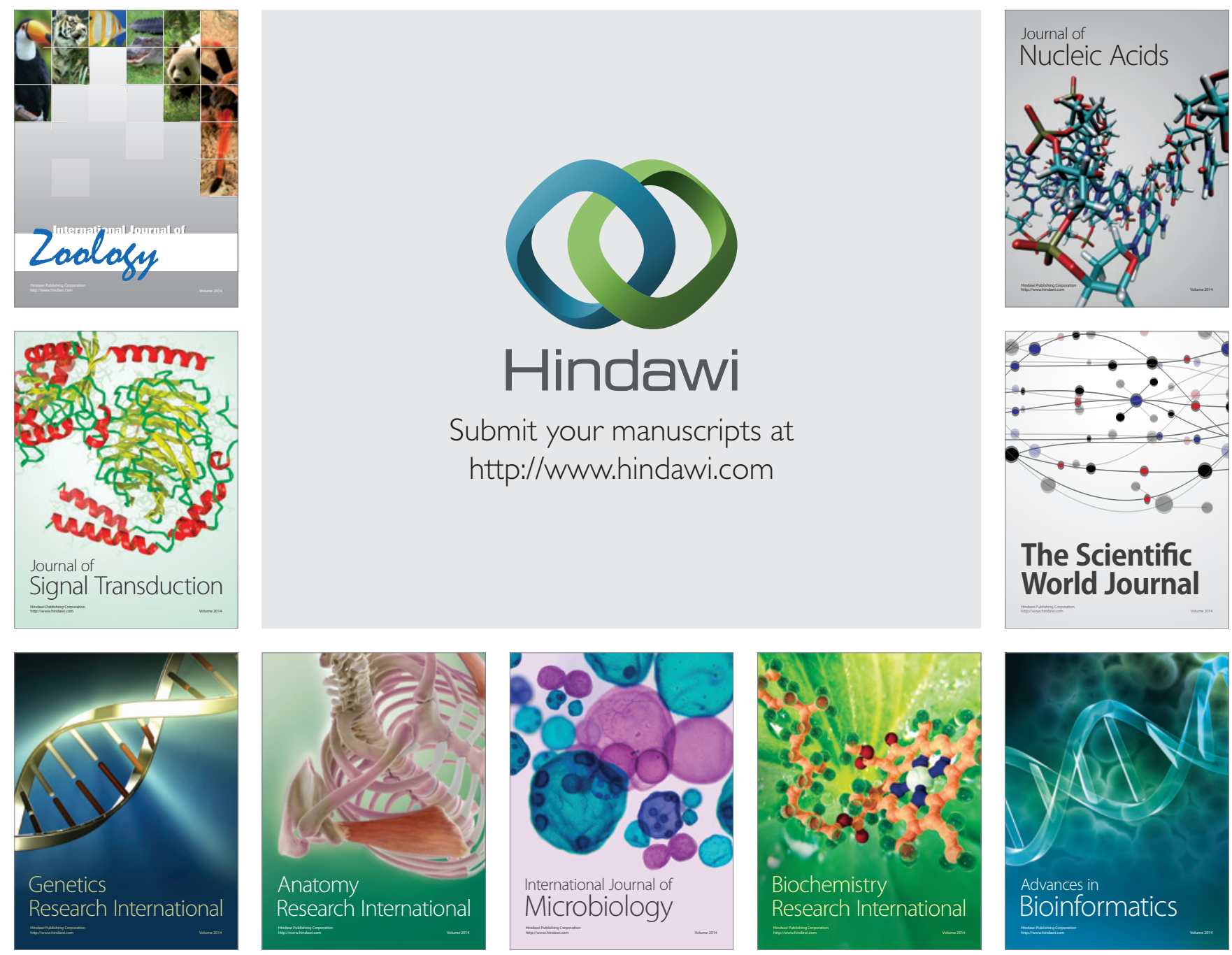

The Scientific World Journal
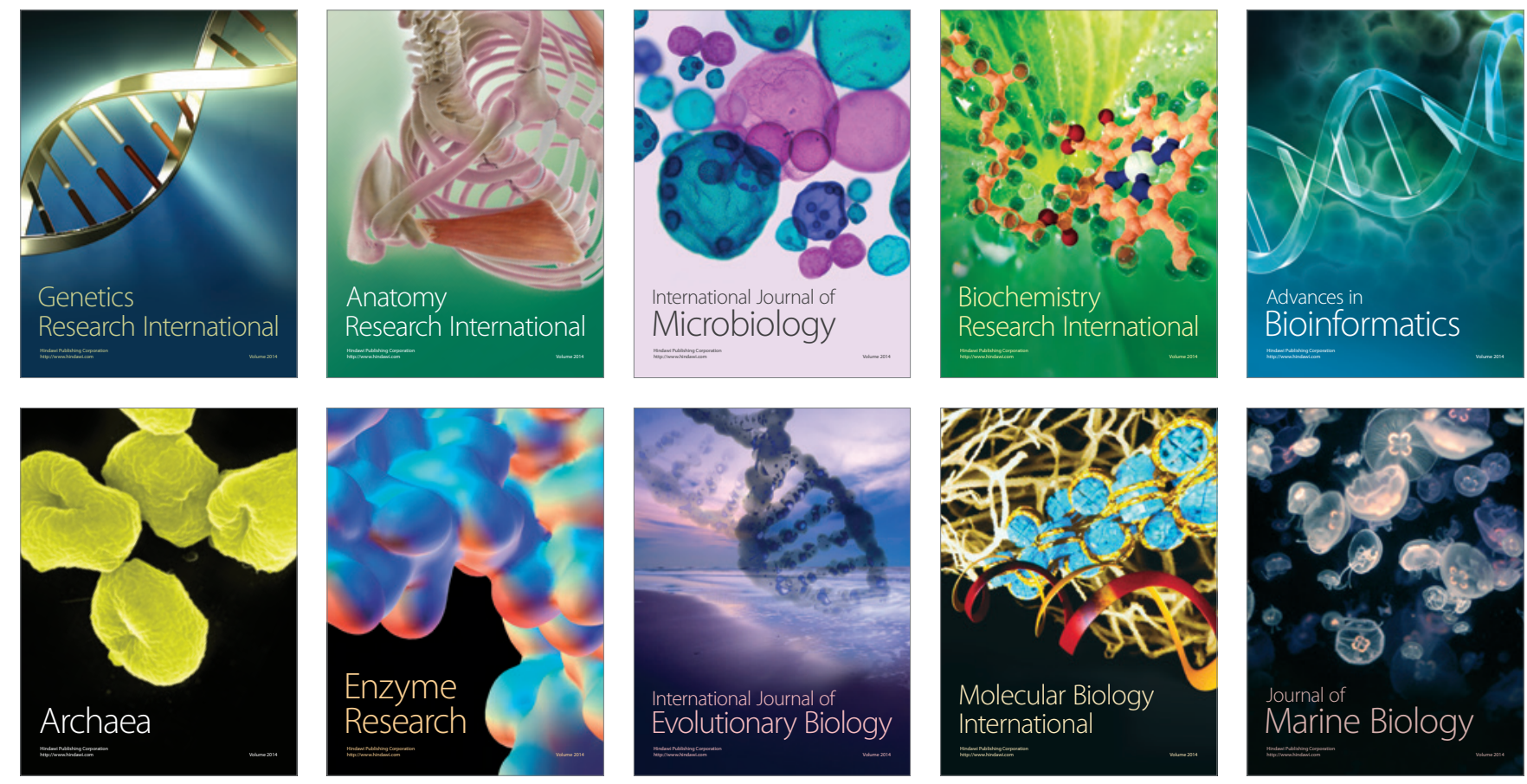